\title{
Influence of Water Irrigation Schemes and Seasonality on Transmission Dynamics of Opisthorchis viverrini in the Snail Intermediate Host, Bithynia siamensis goniomphalos in Rice Paddy Fields in Northeast Thailand
}

\author{
Kulthida Kopolrat, ${ }^{1,2}$ Paiboon Sithithaworn, ${ }^{1,2 \star}$ Nadda Kiatsopit,, 1,2 Jutamas Namsanor, ${ }^{1,2}$ Nonglak Laoprom, ${ }^{3}$ Smarn Tesana, ${ }^{1}$ \\ Ross H. Andrews, ${ }^{2,4,5}$ and Trevor N. Petney ${ }^{4,6}$ \\ ${ }^{1}$ Department of Parasitology, Faculty of Medicine, Khon Kaen University, Khon Kaen, Thailand; ${ }^{2}$ Cholangiocarcinoma Research Institute, Faculty \\ of Medicine, Khon Kaen University, Khon Kaen, Thailand; ${ }^{3}$ Department of Science, Faculty of Science and Engineering, Kasetsart University, \\ Chalermphrakiat Sakon Nakhon Province Campus, Sakon Nakhon, Thailand; ${ }^{4}$ Cholangiocarcinoma Screening and Care Program (CASCAP), Khon \\ Kaen University, Thailand; ${ }^{5}$ mperial College London, Faculty of Medicine, St Mary's Campus, London, United Kingdom; ${ }^{6}$ State Museum of Natural \\ History Karlsruhe, Evolution and Paleontology, Karlsruhe, Germany
}

\begin{abstract}
Opisthorchis viverrini is a fish-borne zoonotic trematode that causes significant public health problems in Southeast Asia. Its life cycle requires Bithynia snails as the first intermediate hosts, fish, and human and/or carnivore hosts. This study assessed impacts of land use practice for rice cultivation and seasonality on the transmission dynamics of $O$. viverrini in Bithynia siamensis goniomphalos in rice paddy field habitats. The transmission of $O$. viverrini cercariae in B. s. goniomphalos was monitored at monthly intervals over a 4-year period from January 2010 to December 2013. From a total of 59,727 snails examined by standard cercarial shedding, the prevalence of 0 . viverrini was $0.7 \%$ (range, $0.0-4.1 \%$ ). The prevalence of $O$. viverrini infection in $B$. s. goniomphalos varied with the amount of rainfall, with peaks of infection occurring in the cool-dry season, that is, after each rainy season. A shift of peak prevalence from cool-dry to hot-dry season observed in 2013 was associated with the increase in preceding water irrigation to support the production of second annual rice crop. Significant positive correlations were found between the prevalence and intensity of cercarial infection and the size of snails. Our results revealed substantial variation between years so that to have a clear understanding of the population dynamics of this complex system, studies should be conducted over an extended period (>1 year). Results from this study highlight that water irrigation schemes in rice paddy cultivation and seasonality have a significant effect on the prevalence of $O$. viverrini in $B$. s. goniomphalos.
\end{abstract}

\section{INTRODUCTION}

Fish-borne zoonotic trematodes (FZTs) are the cause of neglected tropical diseases in more than 18 million people, and more than 500 million people are at risk of infection especially in Asia. ${ }^{1,2}$ The most important FZT endemic in the Lower Mekong region is Opisthorchis viverrini sensu lato (species complex). ${ }^{3}$ In Thailand alone, an estimated eight million people are infected with 0 . viverrini. ${ }^{4}$ Infection with O. viverrini has been implicated as a cause of periductal fibrosis (PDF) and bile duct cancer (cholangiocarcinoma $[\mathrm{CCA}])^{5}$ and less than $10 \%$ of $O$. viverrini-infected individuals finally developed CCA. ${ }^{6} \mathrm{~A}$ mass screening of residents $(n=394,028)$ in endemic areas of opisthorchiasis in northeast Thailand by abdominal ultrasonography showed that $17.0 \%$ had PDF and $1.2 \%$ had suspected CCA. ${ }^{7-9}$ Cholangiocarcinoma is typically diagnosed $20-40$ years after infection, usually during the late stage of the disease, and in this stage, the prognosis is poor, and patient death usually occurs within 3-6 months. ${ }^{10}$

Opisthorchis viverrini has a complex life cycle involving two intermediate hosts and multiple developmental stages. ${ }^{11}$ In brief, embryonated eggs are shed by definitive hosts, including humans, through feces into freshwater habitats occupied by snails, the first intermediate hosts belonging to the genus Bithynia. The eggs are ingested by these snails which then become infected. In the snails, the miracidia hatch and develop into sporocysts. The sporocysts undergo asexual

\footnotetext{
*Address correspondence to Paiboon Sithithaworn, Department of Parasitology and Cholangiocarcinoma Research Institute, Faculty of Medicine, Khon Kaen University, Khon Kaen 40002, Thailand. E-mail: paibsit@gmail.com
}

reproduction through the stages of rediae to cercariae. Subsequently, the cercariae emerge into the water where they actively seek a fresh water fish host belonging to the family Cyprinidae. $^{12}$ By penetrating the skin of these fish, the parasites encyst as metacercariae under the skin or in muscle tissue. Humans acquire the infection by ingesting raw or partially cooked infected fish. ${ }^{13}$ Following ingestion, the metacercariae excyst in the duodenum, and the juvenile flukes migrate to the intrahepatic bile ducts, where they develop into adult hermaphrodite flukes within 4 weeks. The sexually mature adults release eggs which are excreted with the feces into the environment to reach Bithynia snails to complete its life cycle. $^{13}$

There are two species of Bithynia snails currently known in Southeast Asia, namely Bithynia funiculata and Bithynia siamensis. Bithynia siamensis is classified into two different subspecies, Bithynia siamensis siamensis and Bithynia siamensis goniomphalos, based on certain morphological characteristics and differences in geographical distribution. ${ }^{14}$ These species/subspecies are present in O. viverrini-endemic areas in Thailand, that is, $B$. funiculata in the north, $B$. s. siamensis in the central area, and $B$. s. goniomphalos in the northeast Thailand, ${ }^{14}$ and $B$. s. goniomphalos sensu lato ${ }^{15}$ have been reported throughout the Lower Mekong Basin. Bithynia siamensis goniomphalos and $B$. funiculata are most frequently inhabited in shallow freshwater environments such as rice fields, roadside ponds, and irrigation canals with an underlying red-yellow podzolic soil. ${ }^{16,17}$ Land use in terms of rice paddy cultivation, a man-made environmental modification, is a dominant habitat for the Bithynia spp., the first intermediate hosts of $O$. viverrini, which can lead to major changes in the epidemiological dynamics of this parasite, resulting in the largely anthropogenic final phase of its life cycle. ${ }^{18}$ 
In northeast Thailand, the snail intermediate host $B$. $s$. goniomphalos is a critical amplifying agent in transmission of the liver fluke, $O$. viverrini. Snail geographical distribution is also a controlling factor for the spread of opisthorchiasis and subsequent development of CCA. Despite the high prevalence $(>90 \%)$ of $O$. viverrini infection in fish, the prevalence in the snail intermediate host is remarkably low $(<1 \%)$ in the same endemic region. ${ }^{19,20}$ Moreover, Brockelman and oth$\mathrm{ers}^{19}$ reported that prevalence rates of $O$. viverrini in $B$. $s$. goniomphalos in a water body in an endemic area of Khon Kaen Province were $0.11-0.63 \%$ during a 12 -month period and that monthly infection rates fluctuated from $0.03-0.36 \%$. However, the maximum number of $O$. viverrini cercariae shed from an infected $B$. s. goniomphalos is as high as 1,728 cercariae daily, with a total production from one snail host of up to 27,692 cercariae. $^{21}$

For O. viverrini, data on host-parasite interactions in $B$. s. goniomphalos are limited, with most coming from crosssectional surveys on the prevalence of infection. Two recent studies $^{22,23}$ show the potential impacts of seasonality on the prevalence of $O$. viverrini in $B$. s. goniomphalos in rice paddies. Results suggest higher prevalence in winter, the cool-dry season, than other seasons, but these studies were conducted only during a 1-year period and at different times. A previous study by Brockelman and others ${ }^{19}$ conducted 30 years ago in a reservoir in the Chi River wetland over a 4-year period shows similar results for the winter season, although a drought had a substantial influence on the population size of the snails and thus the sample size available to test for O. viverrini prevalence. These studies were all conducted in different wetlands and habitats and had different rice cultivation practices over a 30-year period.

In endemic areas, B. s. goniomphalos have varying $O$. viverrini prevalence levels that are associated with multiple environmental and host factors. ${ }^{24}$ The population dynamics of B. s. goniomphalos snails show fluctuations over the course of a year, depending on rainfall. ${ }^{25}$ Moreover, environmental changes following irrigation development are likely to modify the pattern of distribution of snails and trematodes. ${ }^{26}$ Thailand has launched many water resource development projects to supply more water for agriculture. However, water development projects, both small-scale and large dams, have not only benefited the population but also had adverse effects on human health. ${ }^{27}$

Water resource development by dam construction to supply irrigation water for agricultural land increased the transmission of opisthorchiasis in residents in the irrigated compared with non-irrigated area in northeast Thailand. ${ }^{28,29}$ These findings suggested that water from irrigation created more habitat availability for $B$. s. goniomphalos by activating aestivated snails to emerge from hibernation and undergo growth, development, and reproduction to facilitate the parasite's life cycle. ${ }^{24,30}$ Hence, we hypothesize that in addition to water from the rainy season, water irrigation schemes for rice paddy cultivation may enhance the transmission of $O$. viverrini by increasing the aquatic habitat for the snail population.

To understand the implication of land use practices in rice cultivation in the transmission dynamics of $O$. viverrini, this study investigated the effects of the water irrigation scheme and seasonality on the prevalence of $O$. viverrini cercariae in B. s. goniomphalos in the rice paddy fields. The impacts of environmental conditions related to seasonality, that is, rainfall, temperature, and duration of sunshine, and the size of $B$. s. goniomphalos snails were also evaluated.

\section{MATERIALS AND METHODS}

Study area and sampling periods. The study area was a typical rice paddy habitat for $O$. viverrini, and its intermediate host in Phang Khon district, Sakon Nakhon Province, northeast Thailand, was identified as an endemic area of $O$. viverrini infection in B. s. goniomphalos by Kiatsopit and others. ${ }^{20,22}$ This is one of the irrigated rice cultivation areas receiving water from the Nam Un Dam, Sakon Nakhon Province. The dam's reservoir collects water from Nam Un, a tributary of the Songkram River that originates from the Phu Phan Mountain range. The irrigation network comprises concrete canals and smaller furrows with typical water depths in the order of a meter or less (Figure 1). Major variation in the irrigationinduced flow exists depending on significant rainfall events when the release of water from the Nam Un Dam is stopped, and flow in the canals is primarily due to rainfall. In addition to rainwater, the area is irrigated with water from the dam which allows for planting of two crops of rice per year, that is, a wet season crop in rainy season (June-November) and an extra dry season crop in January (January-April). Consequently, snails are available all year round. Indeed, the rice paddy habitat was chosen for this study as it is known to have a high abundance of $B$. s. goniomphalos. ${ }^{30}$ Similar to other regions in the country, the climate is controlled by tropical monsoons and generally divided into three seasons: the hot-dry season, the rainy season, and cool-dry season that occur from March to May, from June to October, and November to February, respectively. ${ }^{23}$

Samples and data collection. To capture the seasonal and year-to-year variability in the transmission dynamics of O. viverrini in B. s. goniomphalos, a longitudinal study design was conducted. Bithynia siamensis goniomphalos were collected at monthly intervals between January 2010 and December 2013 from the same locality and rice paddy field. Snail sampling was performed manually by two people by handpicking from objects and solid surfaces and by dredging the sediment with a scoop from shallow water for 10-12 sites for 10 minutes/site. The snail samples were cleaned, dried, and placed into plastic bags and transported to the laboratory where they were sorted and identified by standard morphological criteria. ${ }^{31,32}$ We obtained monthly data on air temperature $\left({ }^{\circ} \mathrm{C}\right)$, rainfall $(\mathrm{mm})$, duration of sunshine (hours), and the amount of irrigation water released $\left(\times 10^{5} \mathrm{~m}^{3}\right)$ during January 2010 to December 2013 from the provincial meteorological office of Sakon Nakhon Province and the Royal Irrigation Department which is responsible for the maintenance of the irrigation system in this area. Data for rice production and the paddy area were obtained from the chief of Phang Khon District Agricultural Extension Office, Sakon Nakhon Province.

Screening and emergence of $\boldsymbol{O}$. viverrini cercariae. Screening for trematode infection of the snails was performed by a cercarial shedding method as previously described. ${ }^{22}$ In brief, each snail sample was placed separately in a small plastic container (3-cm diameter by $2.5-\mathrm{cm}$ height) filled with $5 \mathrm{~mL}$ of dechlorinated tap water. The containers were covered with a lid studded with pins to facilitate aeration and to prevent the snail from escaping. The snails were exposed to a light 


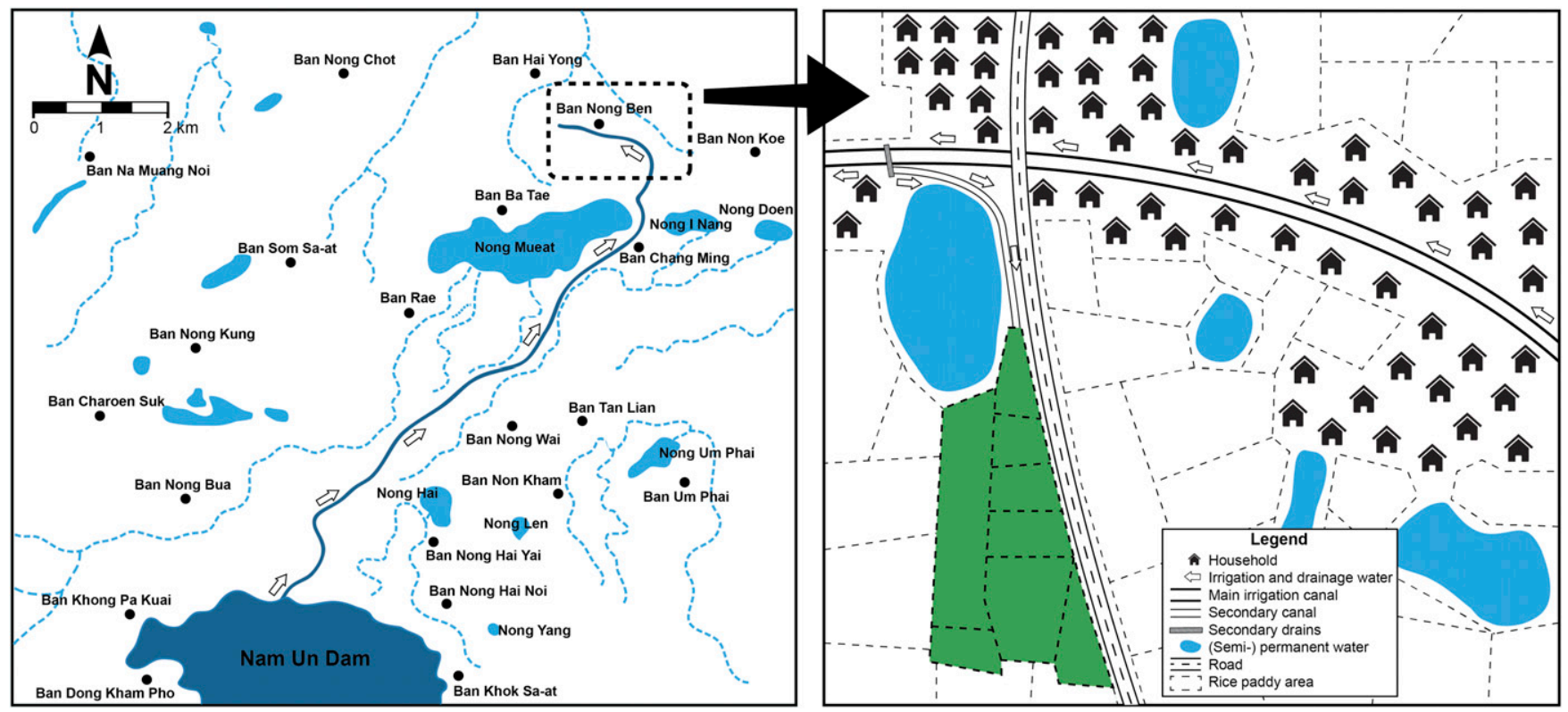

FIGURE 1. Map of the study area showing an overview of the Nam Un Dam and irrigation system, Sakon Nakhon Province, Thailand. The sampling locality for snail collection is highlighted in green. This figure appears in color at www.ajtmh.org.

intensity of 1,200 lux lamps placed $30 \mathrm{~cm}$ above the container for 5 hours during daytime at room temperature $\left(25 \pm 2^{\circ} \mathrm{C}\right)$ within a period of 1 day. The presence of cercariae in water was observed under a stereoscopic microscope and identified by morphological criteria. ${ }^{22,33,34}$ For example, in the case of $O$. viverrini cercariae, they have unique characters of pleurolophocercous type cercariae (based on the body and tail formation) in which the body has two suckers, a primitive gut, two eye spots, five pairs of penetration glands, cystogenous glands, and an excretory bladder. The tail is longer than the body and has a thin fin fold on the dorsal side through the ventral side of the distal part (Supplemental Figure 1). In addition, molecular confirmation of $O$. viverrini cercariae was carried out by a specific polymerase chain reaction (PCR) of the repetitive DNA elements. ${ }^{35-37}$ In addition, a random sample of pleurolophocercous cercariae from snails was passed to fish (silver barb; Barbonymus gonionotus) to obtain O. viverrini metacercariae, which were subsequently fed to hamsters to produce adult worms for definitive identification. ${ }^{38}$ Each batch of snail samples was processed and underwent cercarial shedding within 4 days after collection from the study site.

To estimate the number of cercariae released per day, O. viverrini-positive snails were further kept in the dark for 12 hours and then exposed to light for 12 hours. The numbers of emerging cercariae from each snail over 2-hour intervals were counted under a stereomicroscope after staining with $1 \%$ Lugol's iodine solution. The sums of cercarial emergence over each 12-hour period within a 1-day period were used to calculate cercarial productivity per snail per day. ${ }^{39,40}$

Snail size measurement. The risk of $O$. viverrini infection in B. s. goniomphalos increases with the time of exposure (age of snail) and under natural conditions. The infection was associated with snail size, as the large-sized snails (mature stage) have the highest prevalence of infection. ${ }^{19,20}$ Moreover, the number of cercariae shed increased with snail size. ${ }^{20,23}$ As for previous studies, estimation of snail age was based on the measurements of the shell length. Laboratory data showed that after hatching, the length was $0.7-0.8 \mathrm{~mm}$, and it took 3 months to grow $4 \mathrm{~mm}$ and 6 months to $6-7 \mathrm{~mm} .^{41,42}$ The snails were considered immature or to be of prereproductive age ( $<6 \mathrm{~mm}$ in length or 6 months old) and fully mature or to be of reproductive age ( $>6 \mathrm{~mm}$ in length or $>6$ months old). ${ }^{19}$ The snails can grow larger up to $12-14 \mathrm{~mm}$ in length or 812 months old). Therefore, to observe age-related profiles, shell lengths were grouped in 2-mm increments as less than $4.0 \mathrm{~mm}, 4.1-6.0 \mathrm{~mm}, 6.1-8.0 \mathrm{~mm}, \quad 8.1-10.0 \mathrm{~mm}$, $10.1-12.0 \mathrm{~mm}$, and greater than $12.0 \mathrm{~mm}$.

Within the samples of $B$. s. goniomphalos collected each month, 90-100 uninfected snails were randomly chosen for size measurements. In addition, the $O$. viverrini-positive $B$. $s$. goniomphalos snails found each month (1-63 snails) were recruited for size measurement to estimate size (age)prevalence profiles. The shell lengths were measured from the tip of the apex to the aperture by using digital Vernier calipers. ${ }^{39,40}$ Snail size data were available for a 3-year period, 2011-2013.

Statistical analyses. Data were analyzed using SPSS version 21.0 software (IBM Software Company, Chicago, IL) and Graphpad Prism 5 (La Jolla, CA). Data on the prevalence of trematode cercariae in $B$. s. goniomphalos were calculated as percentage for each cercarial type. Environmental profile data, that is, temperature, rainfall, duration of sunshine, irrigated water, and prevalence and cercarial release/day of $O$. viverrini in $B$. s. goniomphalos were obtained at monthly intervals during the 4-year study period from 2010 to 2013 . Odds ratios (OR) with $95 \% \mathrm{Cl}$ from logistic regression models were calculated to investigate the association between the prevalence of $O$. viverrini and environmental variables, namely, temperature, rainfall, duration of sunshine, irrigation water, and the snail size. Because the prepatent period of $O$. viverrini in $B$. s. goniomphalos is approximately 4 weeks, ${ }^{13,43}$ environmental data were adjusted for a period of 4 weeks before the time of cercarial shedding before being incorporated into the 
logistic regression analyses. Chi-squared tests were used to compare the prevalence of $O$. viverrini in $B$. s. goniomphalos between study years and seasons. Data related to snail size classes for prevalence and cercarial emergence per snail per day in each season were available for 3 years during 2011-2013. Independent two sample $t$-tests were used to assess size differences between groups of infected and uninfected snails at different season. Correlations between
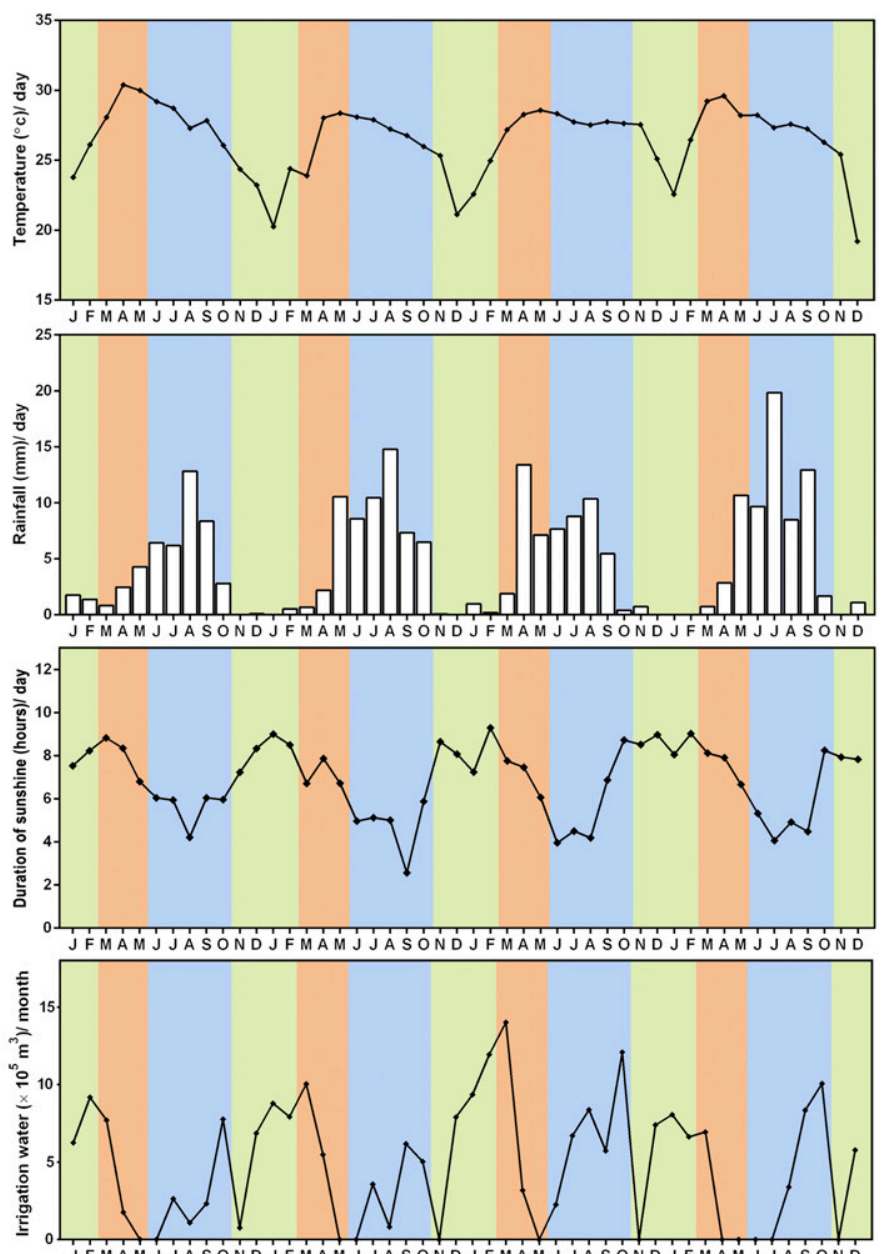

JFMAMJJASOND JFMAMJJASONDJFMAMJJASOND JFMAMJJASOND
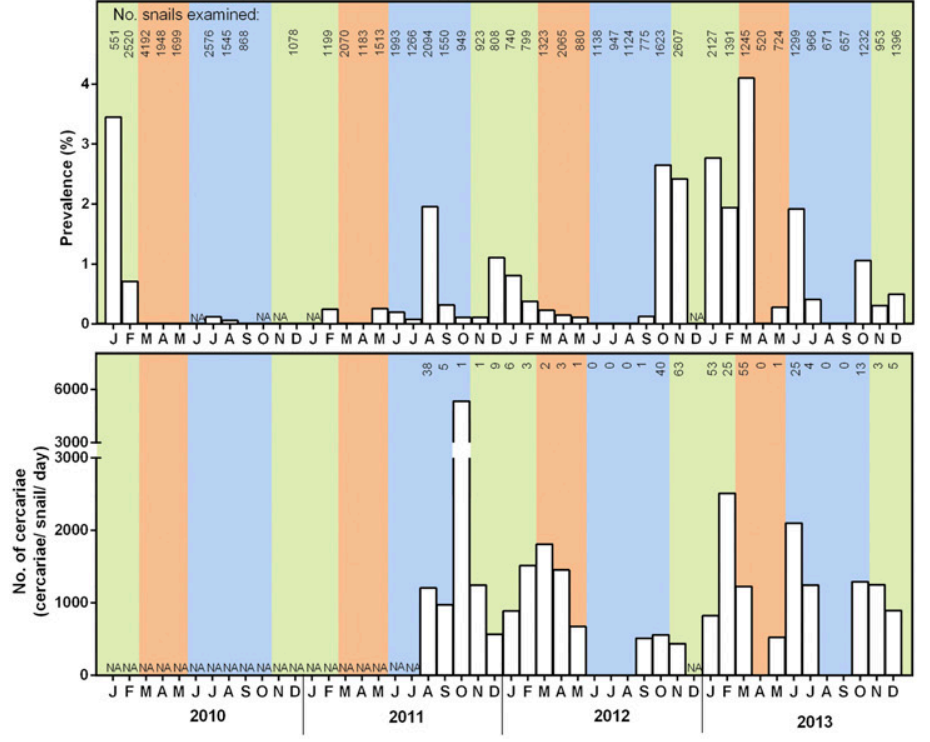

FIGURE 2. Time-profile data of air temperature, rainfall, duration of sunshine, irrigation water, percentages of snails infected with Opisthorchis viverrini, and cercarial emergence at monthly intervals during 2010-2013. Numbers of snails examined at each sampling time are given for percentages of snails infected and cercarial emergence (top of bar graphs). Green color represents the cool-dry season, orange color represents the hot-dry season, and blue color represents the rainy season. This figure appears in color at www.ajtmh.org. 
cercarial emergences/snail/day and snail size classes were evaluated by linear regression and Pearson's correlation coefficient. A $P$-value of $<0.05$ was considered statistically significant.

\section{RESULTS}

Prevalence of trematode cercariae. A total of 59,727 B. s. goniomphalos snails were collected during the 4-year study period, and $10.0 \%$ (range, 1.0-49.2\%) were infected with cercariae of different trematodes. Seventeen morphologically distinct types were found, which could be defined into nine different groups: virgulate (four types), pleurolophocercous (1), cystophorous (2), monostome (1), furcocercous (4), mutabile (1), parapleurolophocercous (1), echinostome (2), and amphistome (1). The virgulate type was the most common group and had the highest prevalence in snails, with a mean of $7.84 \%$. The second most common group was pleurolophocercous (O. viverrini) cercariae, which had an average prevalence of $0.71 \%$. The third most common group was cystophorous cercariae $(0.39 \%)$. Six other types of cercariae were monostome cercariae (prevalence, $0.33 \%$ ), furcocercous cercariae (prevalence, $0.25 \%$ ), mutabile cercariae (prevalence, $0.12 \%$ ), parapleurolophocercous cercariae (prevalence, 0.12 ), echinostome cercariae (prevalence, $0.12 \%$ ), and amphistome cercariae (prevalence, 0.07 ).

Time profiles of environmental factors and 0 . viverrini infection. Over the 4-year period, the patterns of rainfall, duration of sunshine, and temperature were relatively consistent between years, although timing and the amount of irrigated water were highly variable (Figure 2). More irrigated water was released in 2012 than other periods. The prevalence of O. viverrini in B. s. goniomphalos was low (0.34\%) during 2010-2011 but became higher at the start of 2012 and was significantly higher $(P<0.001)$ toward the end of $2012(0.88 \%)$ and remained high until midyear in 2013, with the highest prevalence $(4.10 \%)$ in March 2013 . The average cercarial outputs monitored during August 2011 to December 2013 showed considerable variability, but there were no seasonal differences. The daily average output varied from 435 to 5,341 cercariae/snail/day. The highest output of 5,341 cercariae/ snail/day was found in one snail during the rainy season (October) in 2011.

The prevalence of $O$. viverrini cercariae infection in $B$. $s$. goniomphalos separated by year and season is shown in Figure 3 . The prevalence varied significantly between years, that is, 2010-2013 $(P<0.05)$, and seasons in each year $(P<$ $0.01)$. In 2010, the prevalence peaked in the cool-dry season and was low in the hot-dry and rainy seasons $(P<0.01)$. In 2011 , the prevalence was highest in the rainy season, followed by the cool-dry season, both of which were higher than that found in the hot-dry season $(P<0.001)$. The pattern in 2012 was similar to that in 2010 with the highest prevalence occurring in the cool-dry season compared with the rainy season and the lowest prevalence in the hot-dry season $(P<0.001)$. In 2013 , the highest prevalence was in the hot-dry season. This was significantly greater than those in rainy and cool-dry seasons $(P<0.001)$.

Association between prevalence of $O$. viverrini and environmental variables. To assess the association between season and prevalence of infection, data over a 4-year period were used in the analyses. By using the hot-dry data as the


FIGURE 3. Prevalence of Opisthorchis viverrini during each season for each year of the study showed significant variation. ${ }^{* \star \star}$ Represents a statistical significance of $P<0.001,{ }^{* *}$ represent statistical significance $P<0.01$, ${ }^{*}$ represent statistical significance $P<0.05$.

baseline, there was an increasing trend in the prevalence of infection for the rainy and cool-dry seasons, with odds ratios of 1.80 and 2.07, respectively (Table 1). Moreover, there was a significant $(P<0.001)$ association between the prevalence of 
TABLE 1

Association between Opisthorchis viverrini infection, and seasonal and yearly factors

\begin{tabular}{lccc}
\hline Factor & Odds ratios & $95 \% \mathrm{Cl}$ & $P$-value \\
\hline $\begin{array}{l}\text { Infection } \\
\text { Season }\end{array}$ & 2.254 & $1.957-2.596$ & $<0.001$ \\
Hot-dry & Ref & & \\
Rainy & 1.797 & $1.341-2.409$ & $<0.001$ \\
Cool-dry & 2.067 & $1.800-2.373$ & $<0.001$ \\
Year & 1.857 & $1.690-2.040$ & $<0.001$ \\
2010 & Ref & & \\
2011 & 1.911 & $1.300-2.809$ & 0.01 \\
2012 & 1.986 & $1.664-2.371$ & $<0.001$ \\
2013 & 1.869 & $1.670-2.093$ & $<0.001$ \\
\hline
\end{tabular}

$O$. viverrini in $B$. s. goniomphalos and the study year using 2010 data as a reference with the odds being 1.91, 1.99, and 1.87 for 2011,2012 , and 2013 , respectively.

In Table 2, the OR for the association between the prevalence of infection and environmental factors (lag period of 4 weeks) are presented. There is evidence of an association between temperature and prevalence, when a $1^{\circ} \mathrm{C}$ temperature increase was associated with a $6.7 \%$ increase in the odds of the prevalence of infection $(P<0.05)$. Similarly, the prevalence of infection is significantly associated with increasing rainfall (odds ratio $=1.14,95 \% \mathrm{Cl}=1.09-1.19$ ) and duration of sunshine (odds ratio $=1.83,95 \% \mathrm{Cl}=1.60-2.10$ ). In addition, there was a significant association between the prevalence of infection and level of irrigation water, with the odds being 1.50 and 1.30 for medium and high irrigation water categories, respectively, when compared with the baseline level (irrigation water is measured as $\mathrm{m}^{3}$ ).

Association between $O$. viverrini infection, snail size, and seasonality. Size-related prevalence profiles of $O$. viverrini in $B$. s. goniomphalos were inconsistent between years of study (Figure 4). In 2011 and 2013, the prevalence of infection increased with the size of the snail, that is, prevalence in large snails was higher than that in small snails. On the other hand, in 2012 , the prevalence of infection in small snails was higher than in large snails. When the 3-year data were combined, the prevalence of infection increased significantly with the increasing snail size class $(P<0.05)$, and the chance of finding an infected snail increased with the increasing snail size (Table 3). Snails with a size class over $12.0 \mathrm{~mm}$ had $43 \%$ more chance of being infected (odds ratio $=1.43,95 \% \mathrm{Cl}=1.13-1.80$ ).

A total of 3,674 snails over a 3-year period from 2011-2013 were obtained for size measurements. Of these, 3,293 snails were uninfected and 381 were infected by $O$. viverrini. The snail sizes (shell length) in uninfected and infected snails during the different years and seasons are shown in Figure 5.
In 2011, the infected snails were significantly larger than uninfected snails in all three seasons (two samples $t$-test, $P<$ 0.001). In the following year (2012), the sizes of infected snails were larger than the corresponding uninfected snails only during the hot-day season $(t=3.05, P<0.01$ ), and the sizes became smaller during the rainy and cool-dry seasons. In 2013, the infected snails were larger than uninfected snails in the hot-dry $(t=3.98, P<0.001)$ and the rainy season $(t=3.46$, $P<0.001)$ and were comparable in the cool-dry season.

Over the 3-year period, the size of infected snails ranged from 8.32 to $10.72 \mathrm{~mm}$, with $16.80 \%$ being small snails ( $<8.0 \mathrm{~mm}), 57.22 \%$ medium-sized snails $(8.1-10.0 \mathrm{~mm})$, and $25.98 \%$ large snails (>10.0 mm). Among uninfected snails, the shell size was comparable between each season. The overall size distribution ranged from 8.87 to $9.29 \mathrm{~mm}$, with $16.92 \%$ being small snails $(<8.0 \mathrm{~mm}), 60.61 \%$ medium-sized snails (8.1-10.0 mm), and $22.47 \%$ large snails (> $10.0 \mathrm{~mm})$.

Among the $O$. viverrini-positive $B$. s. goniomphalos snails observed during August 2011 to December 2013 ( $n=357$ ), the shell size significantly correlated with the cercarial output per day $\left(R^{2}=0.177, P<0.001\right)$. When separated by year, the cercarial outputs were significantly correlated with the shell length of the snails in $2011\left(R^{2}=0.623, P<0.001\right), 2012\left(R^{2}=\right.$ $0.064, P<0.01)$, and $2013\left(R^{2}=0.124, P<0.001\right)$ (Figure 6).

\section{DISCUSSION}

Seasonality exerts strong effects on the transmission of FZTs including $O$. viverrini, particularly at the stage from human and animal reservoir hosts to the snail intermediate host, B. s. goniomphalos. ${ }^{24}$ There is a typical seasonal fluctuation in the prevalence of $O$. viverrini in $B$. s. goniomphalos. The high prevalence of infection has been found to occur in the cool-dry season, followed by the hot-dry season, and the prevalence was lowest in the rainy season. ${ }^{20,22,23}$ These studies, however, were conducted either as a single cross-sectional survey or over consecutive seasons in a year; hence, the existence of yearly variation as a consequence of climate changes or flooding was not taken into consideration. Moreover, climatic variables, specifically rainfall and temperature, are known to be associated with differences in snail population size and infection rates, ${ }^{44}$ as well as the dynamics of transmission in other hosts in the life cycle. ${ }^{45,46}$

To capture transmission dynamics data associated with land use practice in rice paddy field habitats, we conducted a longitudinal study design from the same sampling site and found that the prevalence of $O$. viverrini in $B$. s. goniomphalos varied significantly between years, being generally low in 2010-2011 and becoming higher from mid-2012 to 2013. Levels of cercarial output were also variable, ranging between

TABLE 2

Investigation of environmental factors affecting infection of Opisthorchis viverrini in Bithynia siamensis goniomphalos

\begin{tabular}{|c|c|c|c|c|}
\hline Factor & Category & Odds ratios & $95 \% \mathrm{Cl}$ & $P$-value \\
\hline \multicolumn{5}{|l|}{ Infection } \\
\hline Temperature & Continuous & 1.067 & $1.013-1.124$ & 0.05 \\
\hline Rainfall & Continuous & 1.139 & $1.090-1.189$ & $<0.001$ \\
\hline Duration of sunshine & Continuous & 1.830 & $1.595-2.100$ & $<0.001$ \\
\hline \multirow[t]{3}{*}{ Irrigation water } & $\operatorname{Low}\left(0.1-500,000 \mathrm{~m}^{3}\right)$ & 0.961 & $0.652-1.417$ & 0.841 \\
\hline & Medium $\left(500,001-1,000,000 \mathrm{~m}^{3}\right)$ & 1.502 & $1.297-1.738$ & $<0.001$ \\
\hline & High $\left(1,000,001-1,500,000 \mathrm{~m}^{3}\right)$ & 1.300 & $1.156-1.462$ & $<0.001$ \\
\hline
\end{tabular}

Temperature, rainfall, and duration of sunshine were measured and multiple regression applied. Baseline for irrigation water is taken as $0 \mathrm{~m}^{3}$. 
A 2011

No. of snails examined:

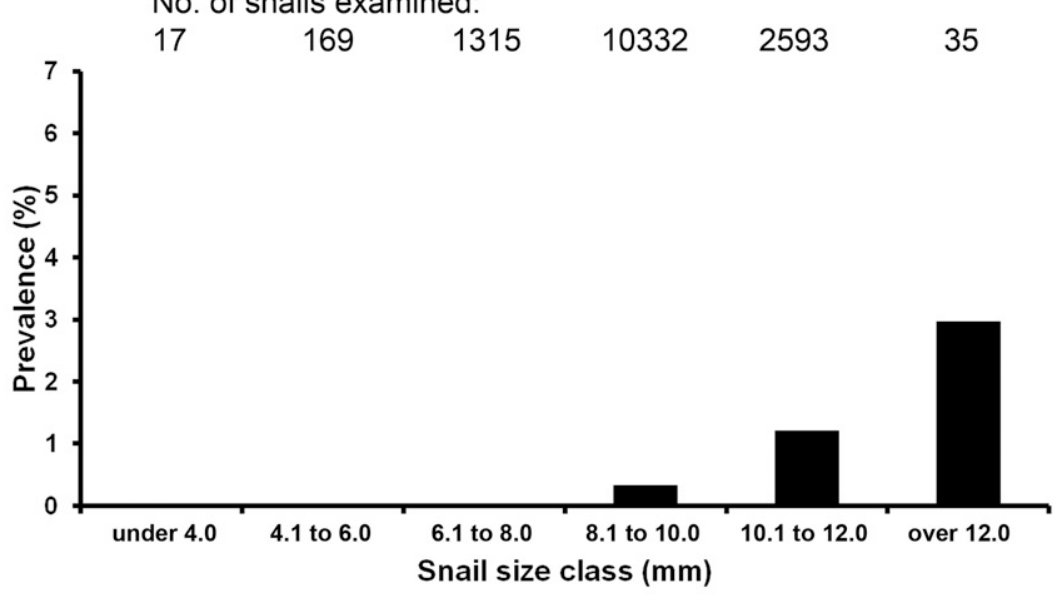

B 2012

No. of snails examined:

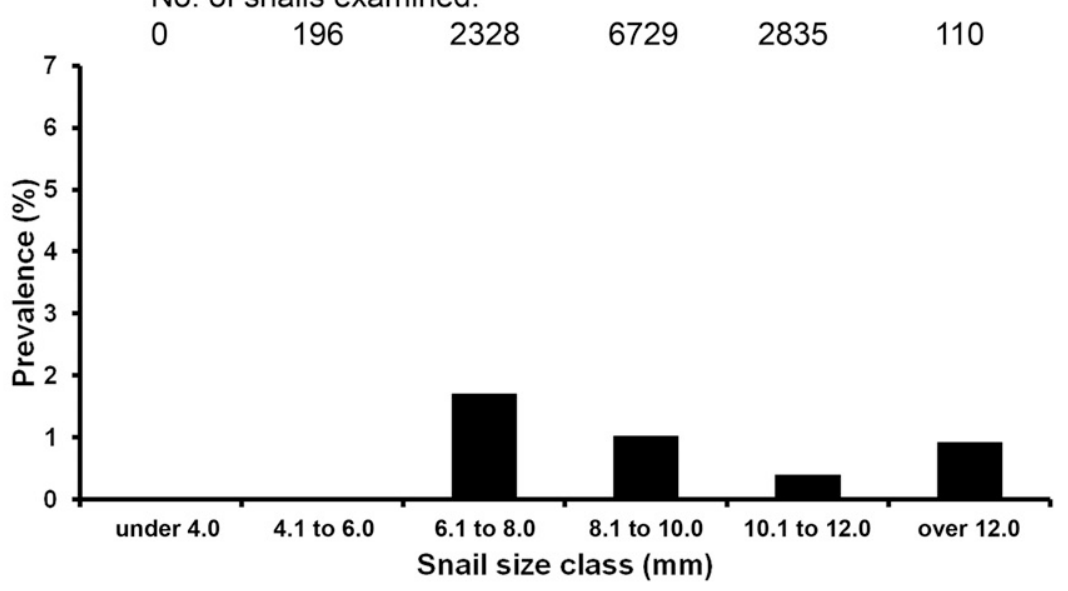

\section{2013}

No. of snails examined:

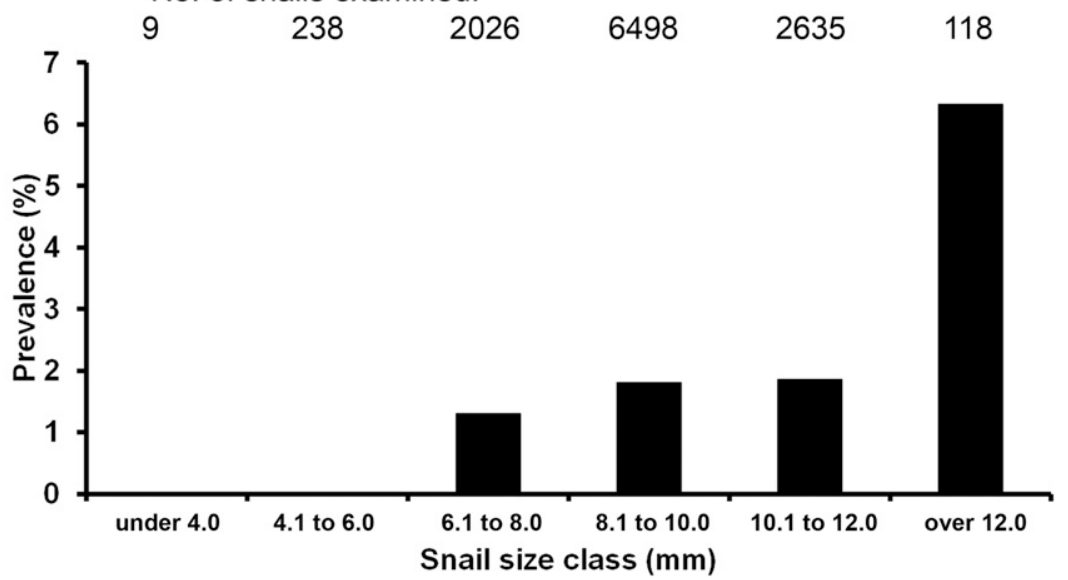

Figure 4. Prevalence of Opisthorchis viverrini infection among field-collected snails of different size classes.

1,000 and 2,000 cercariae/day, except in October in 2011 when an exceptionally high output ( $>5,000$ cercariae/day) was observed. The strongest factor relating to high $O$. viverrini prevalence rates was season, with a high prevalence in the cool-dry season in 2010-2012. However, this is not consistent as prevalence peaked in the hot-dry season in 2013. In addition to environmental factors, our study found that land use in paddy rice cultivation related to irrigation water in 2012 also directly influenced $O$. viverrini prevalence rates in the snails. We found that the increase in the prevalence of $O$. viverrini detected in B. s. goniomphalos coincided with a preceding period of increase in the use of irrigation water 
TABLE 3

Association between the prevalence of Opisthorchis viverrini and snail size class

\begin{tabular}{lcc}
\hline \multicolumn{1}{c}{ Size class $(\mathrm{mm})$} & Odds ratios & $95 \% \mathrm{Cl}$ \\
\hline $6.1-8.0$ & - & Ref \\
$8.1-10.0$ & 0.885 & $0.670-1.170$ \\
$10.1-12.0$ & 1.006 & $0.857-1.181$ \\
Greater than 12.0 & $1.425^{\star}$ & $1.126-1.804$ \\
\hline "Significance $(P<0.01)$. &
\end{tabular}

(45.36-64.67\%) in 2012 compared with that in 2011 and 2013.

This increase was associated with two major events in the transmission dynamics of $O$. viverrini. First, as a consequence of the increase in water availability, double-cropping rice agriculture occurs, with one planting starting in January (dry-season, irrigation-based rice) and the other in June (wetseason rice). Thus, this practice can alter the natural mortality cycle of snails and artificially boost their population density in rice fields. The presence of young or prereproductive snail sizes $(<8.0 \mathrm{~mm})$ resulted in a shift in the prevalence of infection
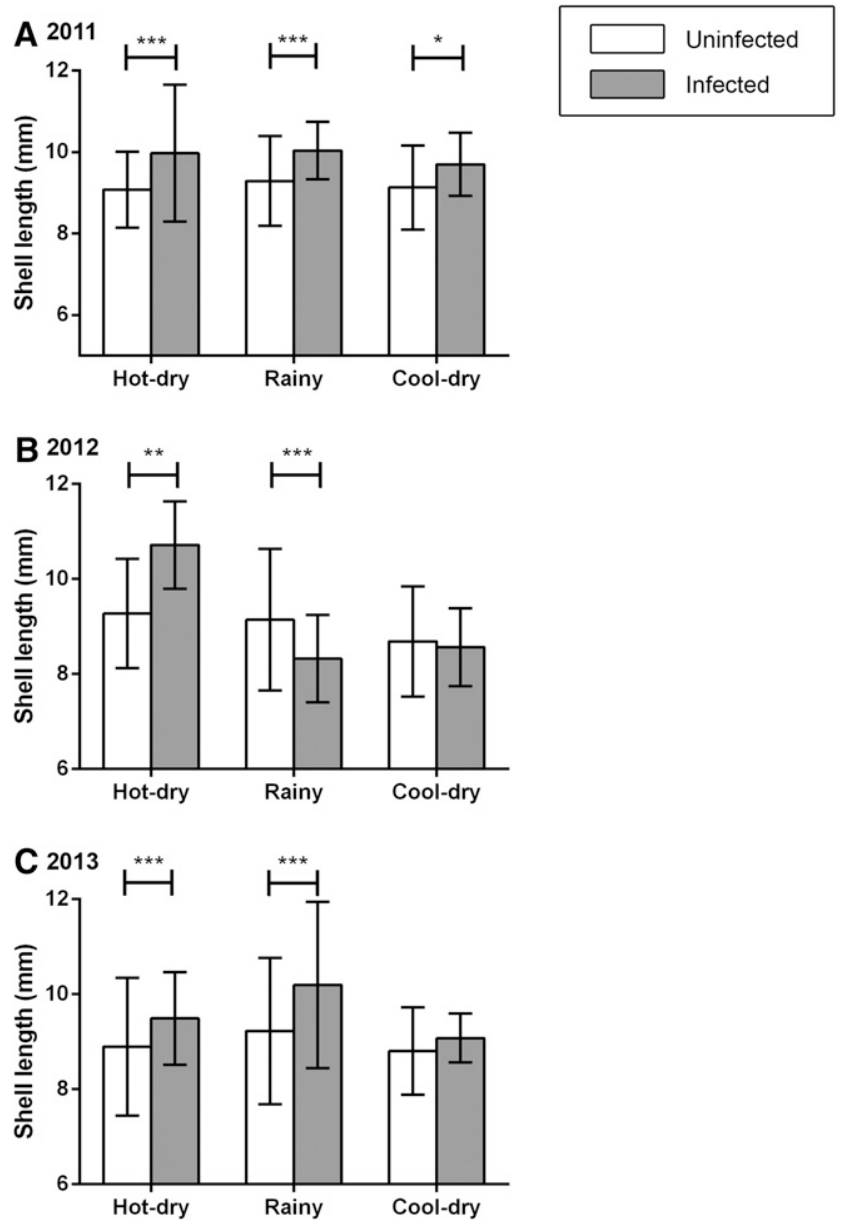

FIGURE 5. Growth parameters of Bithynia siamensis goniomphalos snails in different seasons. Bars show the growth parameter of snails with different infection status, uninfected and infected with Opisthorchis viverrini, Uninfected (white), infected with O. viverrini cercariae (gray). ${ }^{* \star *}$ represents a statistical significance of $P<0.001$, ** represents statistical significance $P<0.01$, * represents statistical significance $P<0.05$

\section{A 2011}

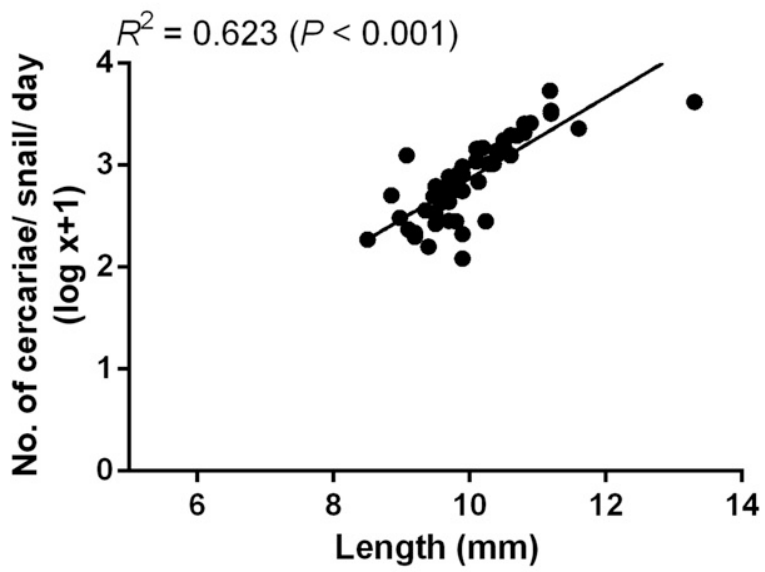

B 2012

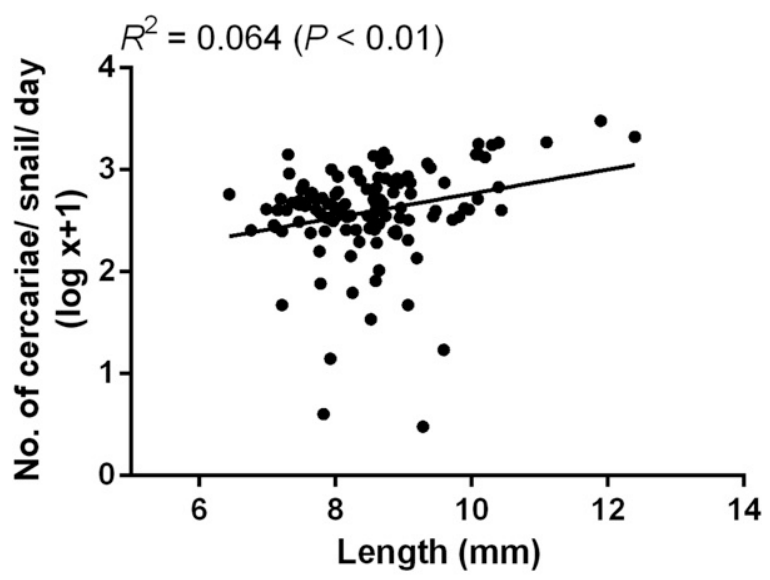

C $\mathbf{2 0 1 3}$

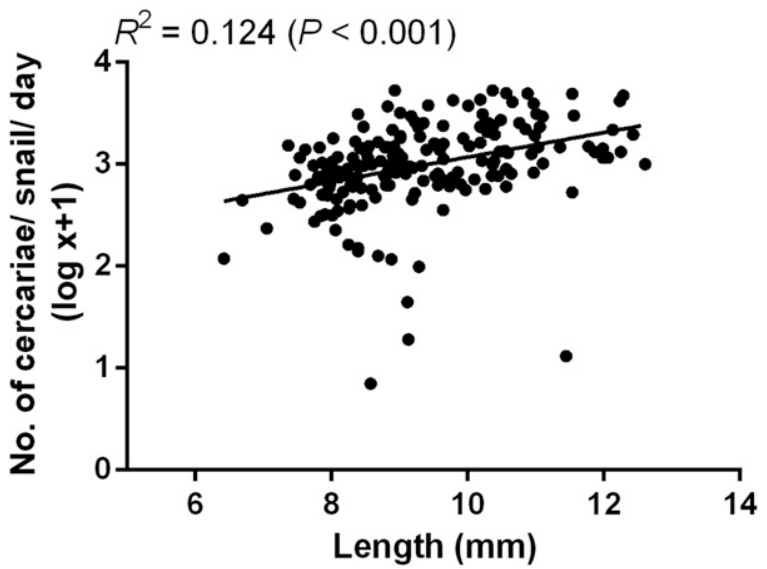

FIGURE 6. Numbers of Opisthorchis viverrini cercariae released/ snail/day in different snail size. There are significant positive correlations between cercarial release and snail size. $R^{2}$ is the correlation coefficient and $P$-value.

from predominantly large $(>8.0 \mathrm{~mm})$ to smaller size snails $(<8.0 \mathrm{~mm})$ in 2012, in contrast to 2011 and 2013. Second, increased irrigation was associated with a higher prevalence in the hot-dry season in 2013 as opposed to the conventional 
peak prevalence in the cool-dry season in 2010 to 2012 . These phenomena are probably due to the fact that irrigation ditches functionally connect human and snail hosts through the transport of feces from households and villages. In areas where sanitary facilities are underdeveloped, human host or domestic reservoir feces containing $O$. viverrini eggs can be flushed into water bodies directly or through irrigation ditches in heavy monsoon rain. Fecal bacterial densities are high in areas with high runoff, ${ }^{47}$ and contamination is greatest during the early part of the rainy season, which coincides with the rapid increase in snail population density. ${ }^{45}$ The possibility that eggs may be carried with irrigation water, as is the case of cercarial infection occurring through contaminated water used to refill aquaculture fish ponds, ${ }^{48}$ is unlikely. Eggs are more likely to sediment quickly and may not disperse over a large distance.

Our findings also highlight the potential influences of land use practice on $O$. viverrini prevalence, for example, changes in agricultural practice due to extensive irrigation. In 2011 and 2012 , the odds for the prevalence of infections in $B$. $s$. goniomphalos were higher than in the other years, corresponding to rice production area (ha) and rice production (tons) in this area (data available from the Chief of Phang Khon District Agriculture Department). This is because, in addition to seasonal crops, the second crops in the cool-dry season allowed greater areas of rice paddy to be used. The practice of irrigating rice paddies using stream or pond water during rice planting seasons can potentially account for the introduction B. s. goniomphalos snails back into areas where they were absent. ${ }^{30}$ This underscores the possible effect of irrigation on O. viverrini transmission, particularly in irrigated areas during the dry seasons, because the presence of snail intermediate hosts and the increase of their population density are not directly related to the natural hydrological input, but are regulated by anthropogenic irrigation practices during rice planting seasons. The proliferation of the first intermediate host of $O$. viverrini can subsequently contribute to the persistence of $O$. viverrini transmission.

The present study revealed that the larger snails had higher prevalence of infection than medium-sized and small snails. This finding, in part, supports a previous study by Upatham and Sukhapanth ${ }^{25}$ on $B$. s. siamensis who found that the largest snails were the most heavily infected. Ngern-klun and others $^{49}$ found that higher prevalence levels occurred in $B$. funiculata at a length of $>7 \mathrm{~mm}$ compared with $\leq 7-\mathrm{mm}$ snails. However, a study by Chanawong and Waikagul ${ }^{41}$ found that immature laboratory-bred Bithynia of the three taxa (2- to 4-mm long) were more susceptible to O. viverrini infection than field-collected snails (6- to $10-\mathrm{mm}$ long). Our results showed that the prevalence of $O$. viverrini was positively associated with the size of $B$. s. goniomphalos in 2011 and 2013 , but the relationship was reversed in 2012 . This may be partially explained by the fact that in 2012 , there were more snails available as a result of more irrigated water; hence, more small snails (prereproductive size) were infected than larger snails in the rainy and cool-dry seasons. Our results showed that there was a relationship between the cercarial emergence of $O$. viverrini and shell size, with cercarial emergence in larger snails being significantly higher than that in medium-sized and small snails. This is possibly because of more volume of soft tissue and hemolymph available to miracidiae in larger snails.

In conclusion, our study revealed that $O$. viverrini infection in its snail host is strongly dependent on water irrigation in paddy rice cultivation and seasonality but also that there was substantial yearly variation. The typically high prevalence during the cool-dry season due to the reduced water volume accompanied by increased density of snail hosts and intensified use of the habitat may shift to the hot-dry season because of irrigation. This anthropogenic environmental manipulation facilitates snail population growth such that high prevalence appeared in small, young snails rather than the typically larger, older snails. Human land use changes caused by irrigation and rice paddy cultivation practice may alter the environment by increasing snail habitats, facilitating egg contamination and therefore $O$. viverrini transmission, particularly to the fish second intermediate host. These changes and practices should be considered in future control programs.

Received April 16, 2019. Accepted for publication March 31, 2020.

Published online May 11, 2020.

Note: Supplemental figure appears at www.ajtmh.org.

Acknowledgments: We acknowledge the support of the Faculty of Medicine, Khon Kaen University, Visiting International Professor Program, and the Cholangiocarcinoma Screening and Care Program (CASCAP), Khon Kaen University. We thank the Provincial Meteorological Office of Sakon Nakhon Province, Thailand, for providing climate and environmental data. We are also grateful to the chief of Phang Khon District Agriculture Department, Sakon Nakhon Province, Thailand, for data for the rice production area and rice production. Data for the irrigation water were supplied by the Royal Irrigation Department, Sakon Nakhon Province, Thailand.

Financial support: This work was supported by the Higher Education Research Promotion and National Research University Project of Thailand, Office of the Higher Education Commission, through the Center of Excellence in Specific Health Problems in Greater Mekong Subregion Cluster (SHeP-GMS, Project no. Ph.D. 54202) and the Invitation Research fund (grant number I 57114) from the Faculty of Medicine, Khon Kaen University, Thailand, the postdoctoral training, Graduate School Khon Kaen University, and the Thailand Research Fund through the Basic Research Grant Scheme (grant number BRG5280021). We would like to thank the Deutsche Forschungsgemeinschaft (PE1611/1-3), the National Research Council of Thailand through the Fluke Free Thailand project, and the International Excellence Fund of the Karlsruhe Institute of Technology as well as the ASEAN-EU Year of Science, Technology and Innovation 2012, for providing funding for cooperative workshops.

Authors' addresses: Kulthida Kopolrat, Paiboon Sithithaworn, Nadda Kiatsopit, and Jutamas Namsanor, Department of Parasitology, Faculty of Medicine, Khon Kaen University, Khon Kaen, Thailand and Liver Fluke and Cholangiocarcinoma Research Institute, Faculty of Medicine, Khon Kaen University, Khon Kaen, Thailand, E-mails: kulthida_kop@yahoo.com, paibsit@gmail.com, nd_tg_na@yahoo.com, and jutamas.namsanor@gmail.com. Nonglak Laoprom, Department of Science, Faculty of Science and Engineering, Kasetsart University, Chalermphrakiat Sakon Nakhon Province Campus, Sakon Nakhon, Thailand, E-mail: nongkku@yahoo.com. Smarn Tesana, Department of Parasitology, Faculty of Medicine, Khon Kaen University, Khon Kaen, Thailand, E-mail: smarn_te@kku.ac.th. Ross H. Andrews, Cholangiocarcinoma Screening and Care Program (CASCAP), Khon Kaen University, Thailand and Imperial College London, Faculty of Medicine, St Mary's Campus, London, United Kingdom, E-mail: rhandrews@gmail.com. Trevor N. Petney, State Museum of Natural History Karlsruhe, Evolution and Paleontology, Karlsruhe, Germany, and Cholangiocarcinoma Screening and Care Program (CASCAP), Khon Kaen University, Thailand, E-mail: trevor.petney@kit.edu.

\section{REFERENCES}

1. WHO, 1995. Control of foodborne trematode infections. World Health Organ Tech Rep Ser 849: 1-157.

2. WHO, 2004. Joint WHO/FAO workshop on food-borne trematode infection in Asia. World Health Organ Tech Rep Ser 3: 1-58. 
3. Sithithaworn P, Andrews RH, Petney TN, Saijuntha W, Laoprom $\mathrm{N}, 2012$. The systematics and population genetics of Opisthorchis viverrini sensu lato: implications in parasite epidemiology and bile duct cancer. Parasitol Int 61: 32-37.

4. Sithithaworn $P$, Andrews RH, Nguyen VD, Wongsaroj T, Sinuon M, Odermatt P, Nawa Y, Liang S, Brindley PJ, Sripa B, 2012. The current status of opisthorchiasis and clonorchiasis in the Mekong Basin. Parasitol Int 61: 10-16.

5. IARC, 2011. A review of human carcinogens: biological agents, Opisthorchis viverrini and Clonorchis sinensis. IARC Monogr Eval Carcinog Risks Hum 100: 351-376.

6. Honjo $S$ et al., 2005. Genetic and environmental determinants of risk for cholangiocarcinoma via Opisthorchis viverrini in a densely infested area in Nakhon Phanom, northeast Thailand. Int J Cancer 117: 854-860.

7. Chamadol N, Khuntikeo N, Thinkhamrop B, Thinkhamrop K, Suwannatrai AT, Kelly M, Promthet S, 2019. Association between periductal fibrosis and bile duct dilatation among a population at high risk of cholangiocarcinoma: a crosssectional study of cholangiocarcinoma screening in Northeast Thailand. BMJ Open 9: e023217.

8. Khuntikeo $\mathrm{N}$ et al., 2018. Current perspectives on opisthorchiasis control and cholangiocarcinoma detection in southeast Asia. Front Med (Lausanne) 5: 117.

9. Kim JY et al., 2018. Ultrasonographic investigation of cholangiocarcinoma in Lao PDR. Acta Trop 182: 128-134.

10. Kamsa-ard S, Wiangnon S, Suwanrungruang K, Promthet S, Khuntikeo N, Mahaweerawat S, 2011. Trends in liver cancer incidence between 1985 and 2009, Khon Kaen, Thailand: cholangiocarcinoma. Asian Pac J Cancer Prev 12: 2209-2213.

11. SaijunthaW, Sithithaworn P, Kaitsopit N, Andrews RH, Petney TN, 2014. Liver flukes: Clonorchis and Opisthorchis. Adv Exp Med Biol 766: 153-199.

12. Haas W, Granzer M, Brockelman CR, 1990. Opisthorchis viverrini: finding and recognition of the fish host by the cercariae. Exp Parasitol 71: 422-431.

13. Kaewkes S, 2003. Taxonomy and biology of liver flukes. Acta Trop 88: 177-186.

14. Petney TN, Andrews RH, Saijuntha W, Tesana S, Prasopdee S, Kiatsopit N, Sithithaworn P, 2018. Taxonomy, ecology and population genetics of Opisthorchis viverrini and its intermediate hosts. Adv Parasitol 101: 1-39.

15. Kiatsopit N, Sithithaworn P, Saijuntha W, Petney TN, Andrews RH, 2013. Opisthorchis viverrini: implications of the systematics of first intermediate hosts, Bithynia snail species in Thailand and Lao PDR. Infect Genet Evol 14: 313-319.

16. Suwannatrai $A$ et al., 2011. Effect of soil surface salt on the density and distribution of the snail Bithynia siamensis goniomphalos in northeast Thailand. Geospat Health 5: 183-190.

17. Wang YC, 2012. Examining landscape determinants of Opisthorchis viverrini transmission. Ecohealth 9: 328-341.

18. Petney TN, Andrews $\mathrm{RH}$, Saijuntha W, Wenz-Mucke A, Sithithaworn $\mathrm{P}$, 2013. The zoonotic, fish-borne liver flukes Clonorchis sinensis, Opisthorchis felineus and Opisthorchis viverrini. Int J Parasitol 43: 1031-1046.

19. Brockelman WY, Upatham ES, Viyanant V, Ardsungnoen S, Chantanawat R, 1986. Field studies on the transmission of the human liver fluke, Opisthorchis viverrini, in northeast Thailand: population changes of the snail intermediate host. Int J Parasitol 16: 545-552.

20. Kiatsopit N, Sithithaworn P, Saijuntha W, Boonmars T, Tesana S, Sithithaworn J, Petney TN, Andrews RH, 2012. Exceptionally high prevalence of infection of Bithynia siamensis goniomphalos with Opisthorchis viverrini cercariae in different wetlands in Thailand and Lao PDR. Am J Trop Med Hyg 86: 464-469.

21. Phongsasakulchoti $P$, Sri-aroon $P$, Kerdpuech $Y, 2005$. Emergence of Opisthorchis viverrini cercariae from naturally infected Bithynia (Digoniostoma) siamensis goniomphalos. Southeast Asian J Trop Med Public Health 36 (Suppl 4): 189-191.

22. Kiatsopit N, Sithithaworn P, Kopolrat K, Namsanor J, Andrews $\mathrm{RH}$, Petney TN, 2015. Trematode diversity in the freshwater snail Bithynia siamensis goniomphalos sensu lato from Thailand and Lao PDR. J Helminthol 1-9.

23. Namsanor J, Sithithaworn $P$, Kopolrat K, Kiatsopit N, Pitaksakulrat O, Tesana S, Andrews RH, Petney TN, 2015.
Seasonal transmission of Opisthorchis viverrini sensu lato and a lecithodendriid trematode species in Bithynia siamensis goniomphalos snails in northeast Thailand. Am J Trop Med Hyg 93: 87-93.

24. Petney T, Sithithaworn P, Andrews R, Kiatsopit N, Tesana S, Grundy-Warr C, Ziegler A, 2012. The ecology of the Bithynia first intermediate hosts of Opisthorchis viverrini. Parasitol Int 61: 38-45.

25. Upatham ES, Sukhapanth N, 1980. Field studies on the bionomics of Bithynia siamensis siamensis and the transmission of Opisthorchis viverrini in Bangna, Bangkok, Thailand. Southeast Asian J Trop Med Public Health 11: 355-358.

26. Patz JA, Graczyk TK, Geller N, Vittor AY, 2000. Effects of environmental change on emerging parasitic diseases. Int $J$ Parasitol 30: 1395-1405.

27. Sithithaworn P, Petney TN, Andrews RH, 2015. What significance do helminths species-complexes have for the prevention, diagnosis and treatment of human infections? Trans $R$ Soc Trop Med Hyg 109: 289-290.

28. Sornmani S, Vivatanasesth $\mathrm{P}$, Bunnag T, Intarakhao C, Harinasuta C, 1973. A study on the pattern of socioeconomic and health status in relation to parasitic diseases in the inhabitants around Ubolratana Dam in northeast Thailand. Southeast Asian J Trop Med Public Health 4: 421-434.

29. Sornmani S, Vivatanasesth $P$, Impand $P$, Phatihatakorn $W$, Sitabutra P, Schelp FP, 1984. Infection and re-infection rates of opisthorchiasis in the water resource development area of Nam Pong project, Khon Kaen Province, northeast Thailand. Ann Trop Med Parasitol 78: 649-656.

30. Wang YC, Ho RC, Feng CC, Namsanor J, Sithithaworn P, 2015. An ecological study of Bithynia snails, the first intermediate host of Opisthorchis viverrini in northeast Thailand. Acta Trop 141: 244-252.

31. Brandt RAM, 1974. The non-marine aquatic Mollusca of Thailand. Archiv für Molluskenkunde 105: 1-423.

32. Chitramvong YP, 1992. The Bithyniidae (Gastropoda: Prosobranchia) of Thailand: comparative external morphology. Malacol Rev 25: 21-38.

33. Ditrich O, Nasincova V, Scholz T, Giboda M, 1992. Larval stages of medically important flukes (Trematoda) from Vientiane province, Laos. Part II. Cercariae. Ann Parasitol Hum Comp 67: 75-81.

34. Schell SC, 1970. How to Know the Trematode. Dubuque, IA: WMC Brown Company Publishers, 355.

35. Sermswan R, Mongkolsuk S, Panyim S, Sirisinha S, 1991. Isolation and characterization of Opisthorchis viverrini specific DNA probe. Mol Cell Probes 5: 399-407.

36. Wongratanacheewin S, Pumidonming W, Sermswan RW, Maleewong W, 2001. Development of a PCR-based method for the detection of Opisthorchis viverrini in experimentally infected hamsters. Parasitology 122: 175-180.

37. Young ND et al., 2014. The Opisthorchis viverrini genome provides insights into life in the bile duct. Nat Commun 5: 4378.

38. Kopolrat K, Sithithaworn P, Kiatsopit N, Pitaksakulrat O, Tesana S, Andrews RH, Petney TN, 2016. Comparison of infectivity, metacercarial burden and host mortality induced by Opisthorchis viverrini sensu lato cercariae from Lao PDR compared with Thailand in cyprinid fish, Barbonymus gonionotus. Trans $R$ Soc Trop Med Hyg 110: 46-54

39. Kiatsopit N, Sithithaworn P, Kopolrat K, Andrews RH, Petney TN, 2014. Seasonal cercarial emergence patterns of Opisthorchis viverrini infecting Bithynia siamensis goniomphalos from Vientiane Province, Lao PDR. Parasit Vectors 7: 551.

40. Laoprom N, Kiatsopit N, Sithithaworn P, Kopolrat K, Namsanor J, Andrews RH, Petney TN, 2016. Cercarial emergence patterns for Opisthorchis viverrini sensu lato infecting Bithynia siamensis goniomphalos from Sakon Nakhon Province, Thailand. Parasitol Res 115: 3313-3321.

41. Chanawong A, Waikagul J, 1991. Laboratory studies on hostparasite relationship of Bithynia snails and the liver fluke, Opisthorchis viverrini. Southeast Asian J Trop Med Public Health 22: 235-239.

42. Kruatrachue $M$, Jantataeme $S$, Ratanatham S, Vichasri S, Upatham ES, 1982. A culture method for Bithynia (Prosobranchia: 
Bithyniidae), snail hosts for thetrematode Opisthorchis viverrini. Malacol Rev 15: 63-67.

43. IARC, 2012. A review of human carcinogens: biological agents. IARC Monogr Eval Carcinog Risks Hum 100: 1-441.

44. Sturrock R, 1993. The Parasites and Their Life Cycles, the Intermediate Hosts and Host-Parasitic Relationships. Oxon, United Kingdom: CAB International Press, 33-85.

45. Sithithaworn P, Pipitgool V, Srisawangwong T, Elkins DB, Haswell-Elkins MR, 1997. Seasonal variation of Opisthorchis viverrini infection in cyprinoid fish in north-east Thailand: implications for parasite control and food safety. Bull World Health Organ 75: 125-131.

46. Vichasri S, Viyanant V, Upatham ES, 1982. Opisthorchis viverrini: intensity and rates of infection in cyprinoid fish from an endemic focus in Northeast Thailand. Southeast Asian J Trop Med Public Health 13: 138-141.

47. Gannon JJ, Busse MK, 1989. E. coli and enterococci levels in urban stormwater, river water and chlorinated treatment plant effluent. Water Res 23: 1167-1176.

48. Skov J, Kania PW, Dalsgaard A, Jorgensen TR, Buchmann K 2009. Life cycle stages of heterophyid trematodes in Vietnamese freshwater fishes traced by molecular and morphometric methods. Vet Parasitol 160: 66-75.

49. Ngern-klun R, Sukontason KL, Tesana S, Sripakdee D, Irvine $\mathrm{KN}$, Sukontason K, 2006. Field investigation of Bithynia funiculata, intermediate host of Opisthorchis viverrini in northern Thailand. Southeast Asian J Trop Med Public Health 37: 662-672. 